\title{
Patents and Competitive Awards of the Innovative Elderly Products Designed by Nursing Faculty and Students in Taiwan
}

\author{
Ya-Lie Ku ${ }^{* 1}$, Yi-Ting Pan $^{2}$, Jo-Yun Shia ${ }^{3}$, Yi-Lun $\mathrm{Li}^{4}$, Shu-Ting $\mathrm{Hsu}^{5}$ \\ ${ }^{*}$ RN, MSN, Associate Professor, Department of Nursing, Fooyin University \\ ${ }^{2,3,4,5}$ RN, BSN, Department of Nursing, Fooyin University
}

\begin{abstract}
Because of the aged society in Taiwan, the principal investigator has conducted four innovative projects to develop the four elderly innovative products with four groups of leaders. This paper introduces four innovative elderly products designed by the nursing faculty and students in Taiwan, including modified enema device, combination of turning and positioning auxiliary devices, and urine catheter fixation device for the bedridden elders. Four innovative elderly products have obtained the patents as well as awarded in 2017 International Innovation and Invention Competition by the organizations of Chinese Innovation and Invention Society and Moscow International Invention Society. Following the four innovative elderly products, the investigator would plan to conduct the evidences-based testing of the effectiveness for these products to improve the quality of care for the bedridden elders in terms of preventing or solving their clinical problems such as bedsores, constipation, and comfort.
\end{abstract}

\section{Keywords: Innovative Products, Elderly, Patents, Nursing}

\section{Introduction}

Aging is the global and universal phenomena all over the world. Since 1993, Taiwan has become an aging society, aged society in 2018, and will be the super aged society in 2026..$^{[1,2]}$ Therefore, the elderly products are also developed fast in terms of quality and quantity in Taiwan. For instance, the enema device for the bedridden elders is to eliminate the stool daily so that their stomachs and intestines could feel comfortable for digestion of daily foods. Additionally, the auxiliary devices of turning and positioning for care workers to assist the bedridden elders to lie or turn on the bed in the correct and easy way for the purpose of prevention the bed sores. Finally, the urine catheter fixation device is for the elders who are used the installation urine bag for a long time. Instead of being fixed by $3 \mathrm{M}$ for the urine catheter, the modified fixation device would not touch the skin of the elders directly, which could reduce the possibility of producing the bedsores for the bedridden elders.

\section{Methods}

A nursing practicum project course involving creative thinking teaching of nursing students by nursing faculties has developed and tested the effectiveness of this course in the Department of Nursing at Fooyin University in Taiwan. ${ }^{[3,4]}$ Through the nursing practicum project course, nursing faculties and students have created many innovative products for the purpose of applying the patents and obtaining the awards from the domestic and foreign innovative competitions. Because of the aged society in Taiwan, the principal investigator has conducted four innovative projects to develop the four elderly innovative products with four groups of leaders.
Initially, the investigator would discuss the clinical plights for the bedridden elders with each group and analyze the related factors by brainstorming. Lately each group would design the first draft of innovative product based on the related factors of influencing the clinical plights for the bedridden elders. Additionally, each group would start to search, analyze, and compare the existed products from the internet and patent systems with the first draft of innovative product in terms of its strengths and weakness. Then the second draft of innovative product would be generated along with the benefits based on the information from the internet and patent systems. Furthermore, each group would change and revise the design of the second draft of innovative product during the process of making the real products due to the barriers of materials, prices, and applications. The final design of innovative product for the bedridden elders with each group would be coming up through the cycle of process in discussing, brainstorming, and revising continuously until the final innovative product shown up.

\section{Results}

The four innovative elderly products designed by the investigator and students in Taiwan have owned the patents and awards as following:

\section{Modified Enema Device}

This innovation is a modified enema device product mainly for long-term bedridden elders. This product is the combination of anal canal (length $9 \mathrm{~cm} \mathrm{x}$ width $0.7 \mathrm{~cm}$ ), anal holder (length $9.5 \mathrm{~cm} \mathrm{x}$ width $7.5 \mathrm{~cm})$, and the pumping bottle $(22 \mathrm{~cm})$ with total $37 \mathrm{~cm}$. The first step is to pour the enema solution into the pumping bottle (glycerol + water in accordance with the ratio of 1: 1 deployment) 
and use the vaseline to lubricate the anal holder and anal canal. The second step is to hold the anus by the anal holder, slowly push the anal canal into the elder's anus, and squeeze the pumping bottle to push the liquid into the elder's intestines. The third step is to separate the anal canal from the pumping bottle, but still continued to hold the anus by the anal holder, and the elder's feces could naturally be eliminated after about 30 seconds. The following is the design, real product, and patent of the modified enema device. ${ }^{[5]}$
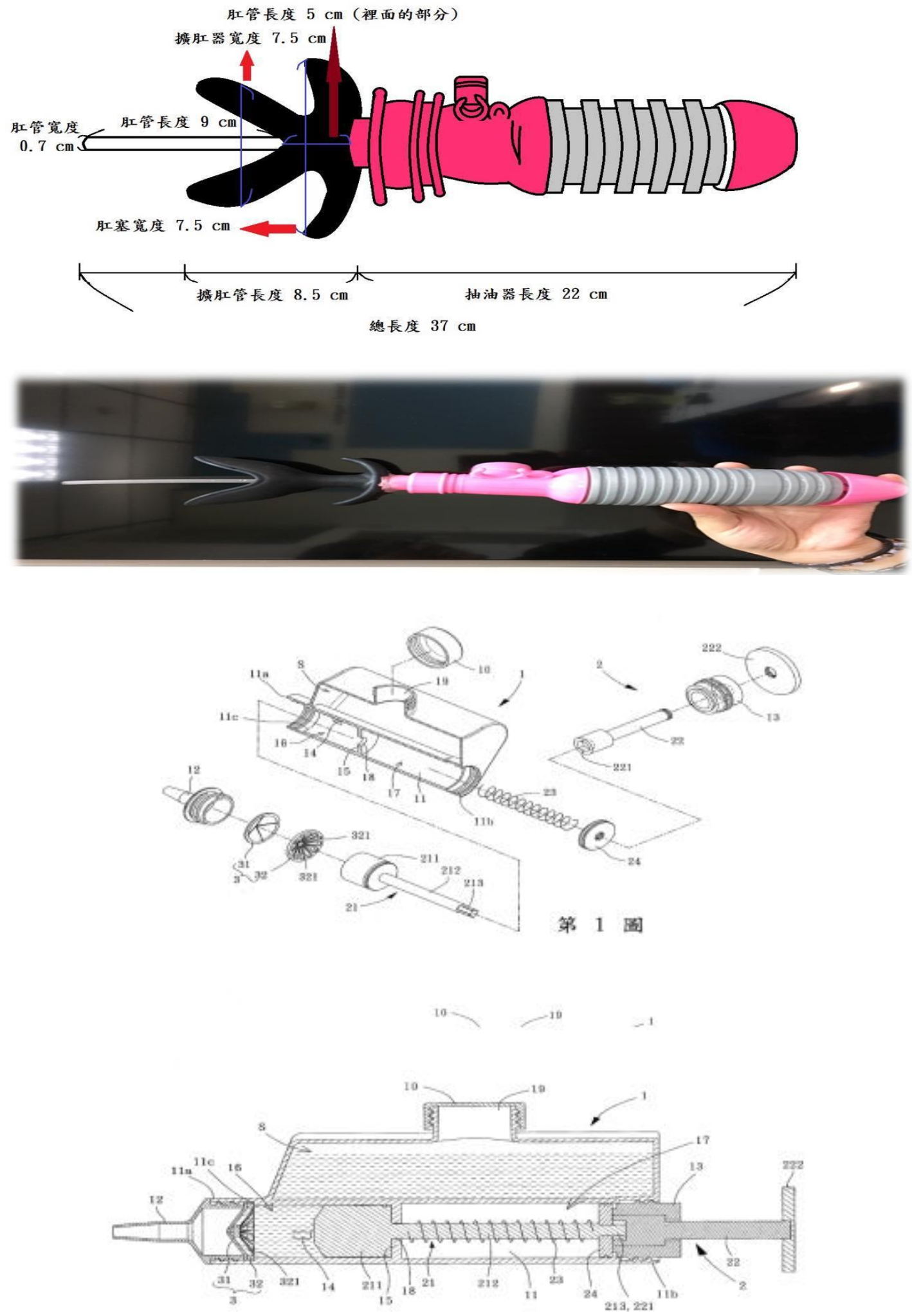

第 2 圖

This innovation is designed for the problems of elderly constipation and fecal stones. The characteristics of this product include a anal holder to hold the anus for preventing enema liquid outflow and keep the enema liquid in the intestine longer enough to soft the fecal stones for eliminating easily. Because this product could be exchanged for anal canal, the anal holder and pumping bottle could be reused after cleaning with the environmental benefits. 
International Journal of Innovative Research in Medical Science (IJIRMS)

Volume 03 Issue 08 August 2018, ISSN: 2455-8737, Imp. Factor - 4.102

Available online at - $w w w$.ijirms.in

Modified Combination of Turning and Positioning Auxiliary Device

The modified combination of turning and positioning auxiliary device included two products. The first product uses $140 \mathrm{~cm}$ length* $90 \mathrm{~cm}$ width cotton fabric combination denim with a $58 \mathrm{~cm}$ length $* 90 \mathrm{~cm}$ width tarpaulins under the elder's hips. The 日word buckles on four sides of the fabric were attached with the four sides of a $24 \mathrm{~cm}$ length* $38 \mathrm{~cm}$ width $\mathrm{cm}$ pillows by the nylon ropes and bean buckles. The following is the design, real product, patent of the first product of turning and positioning auxiliary device. $^{[6]}$
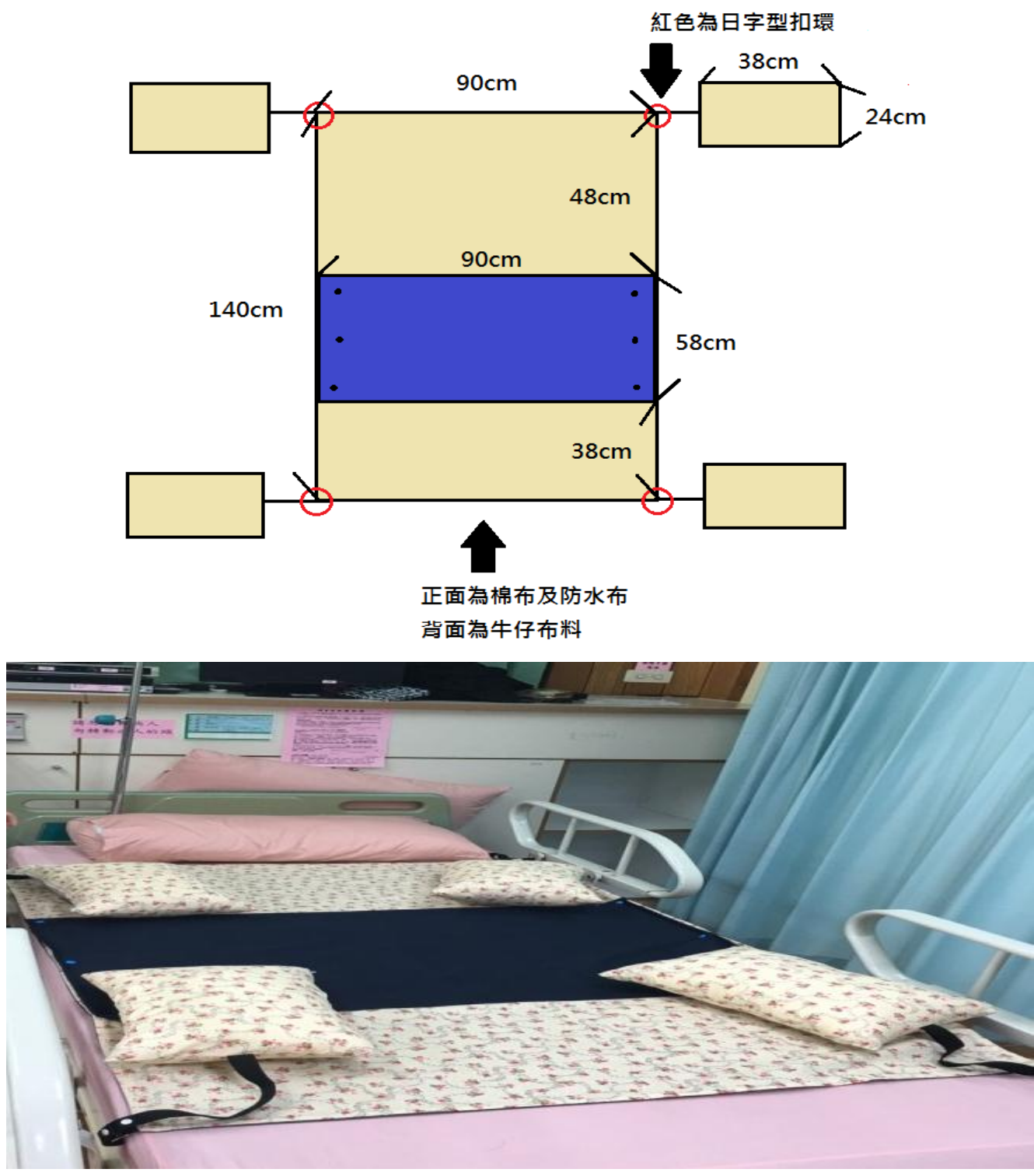

(2)

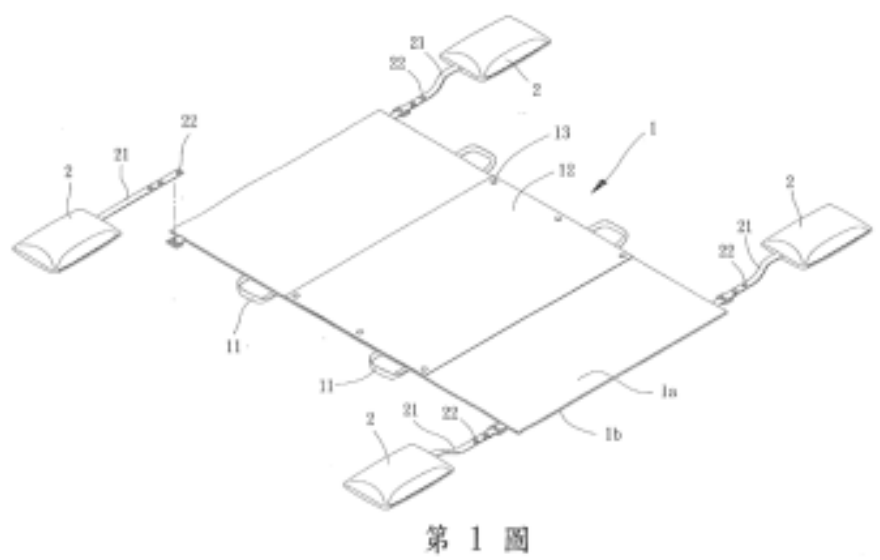




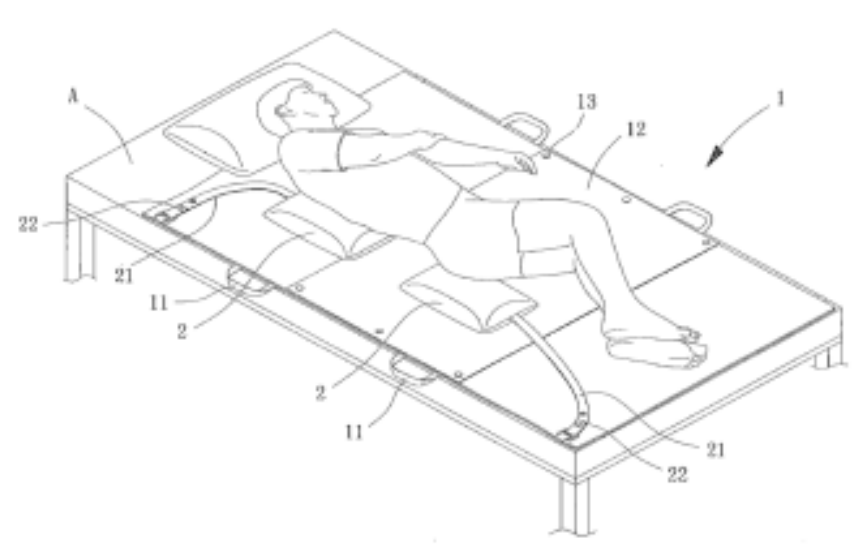

The second product uses $110 \mathrm{~cm}$ length $* 50 \mathrm{~cm}$ width cotton fabric combination denim with a $40 \mathrm{~cm}$ length $* 80 \mathrm{~cm}$ width $\mathrm{cm}$ tarpaulin under the elder's hips, including a $100 \mathrm{~cm}$ length $* 30 \mathrm{~cm}$ width $* 6 \mathrm{~cm}$ height $\mathrm{J}$-shape pillow in the middle of the cotton fabric combination denim. Additionally, the combination of $40 \mathrm{~cm}$ length $* 70 \mathrm{~cm}$ width and $30 \mathrm{~cm}$ length $* 50 \mathrm{~cm}$ width pillows in the up and down of the J-shape pillow. The following is the design, real product, and patent of the second product of turning and positioning auxiliary device. ${ }^{[7]}$
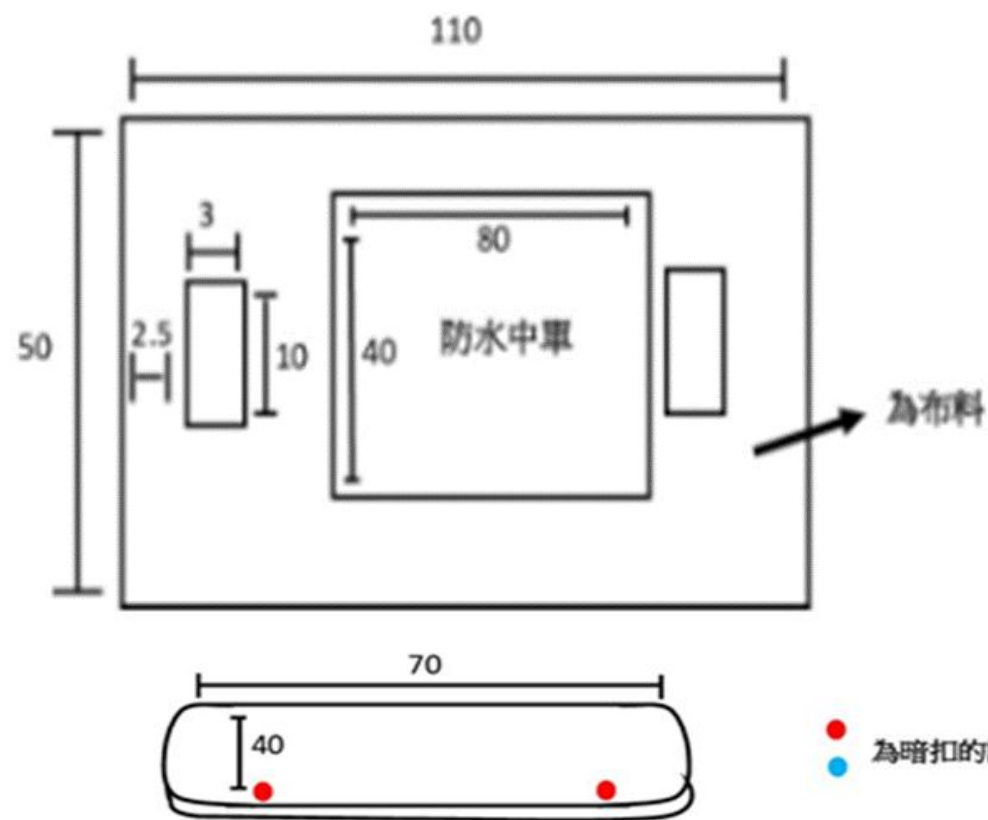

鸟觜扣的設計

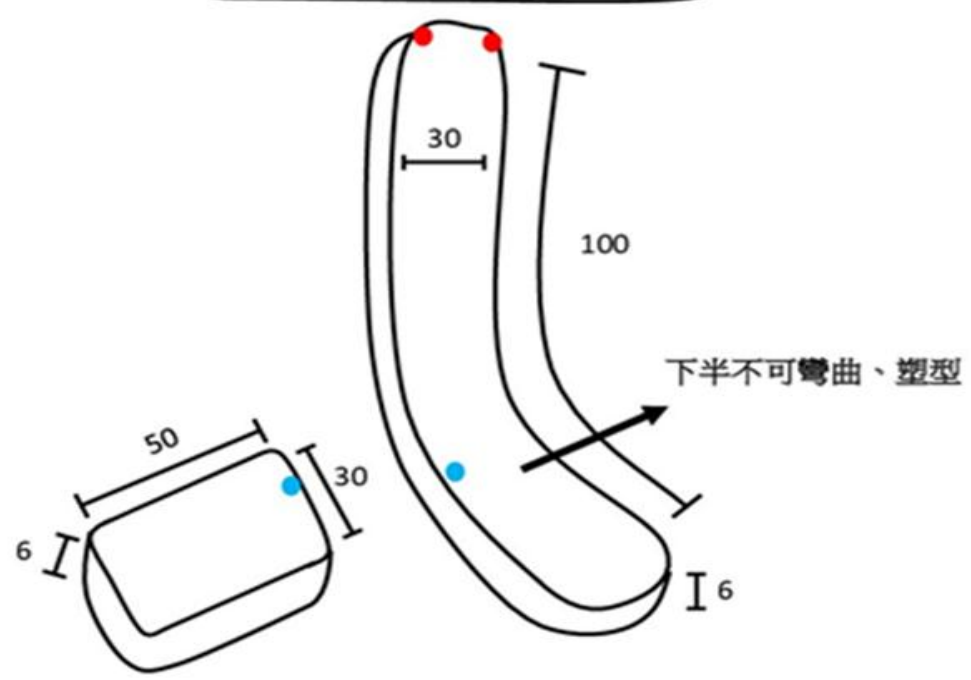


International Journal of Innovative Research in Medical Science (IJIRMS)

Volume 03 Issue 08 August 2018, ISSN: 2455-8737, Imp. Factor - 4.102

Available online at - $\underline{w w w . i j i r m s . i n}$

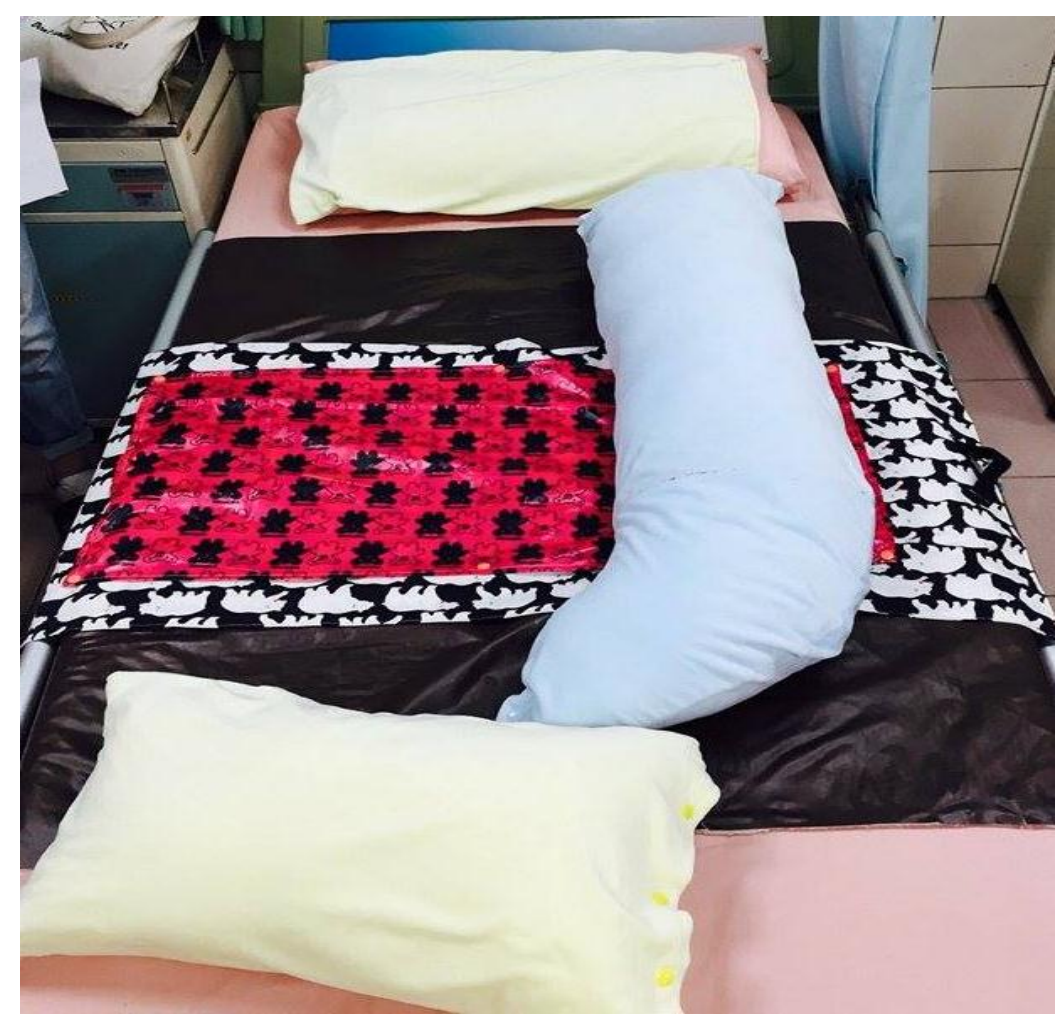

c)

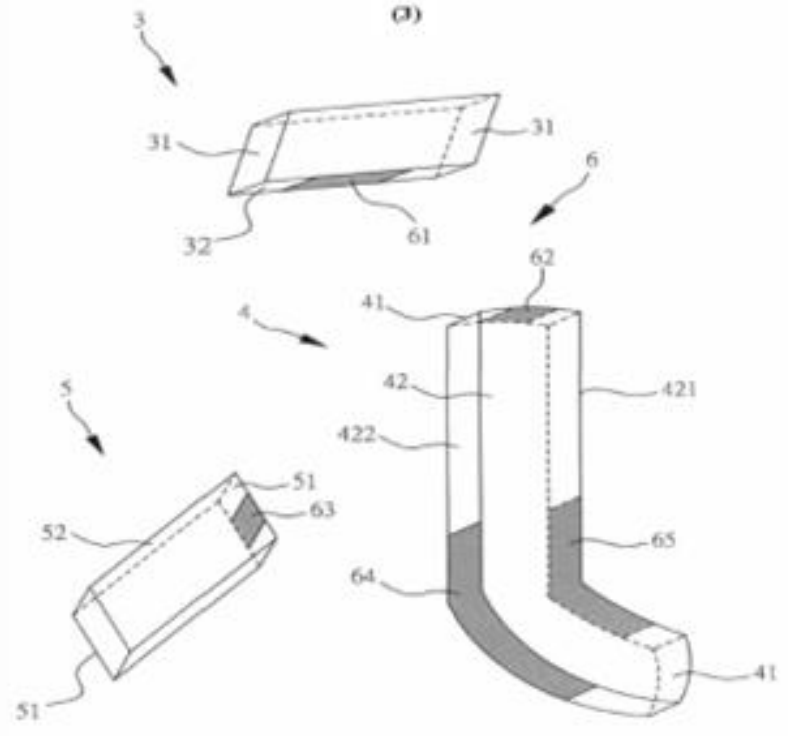

(4)

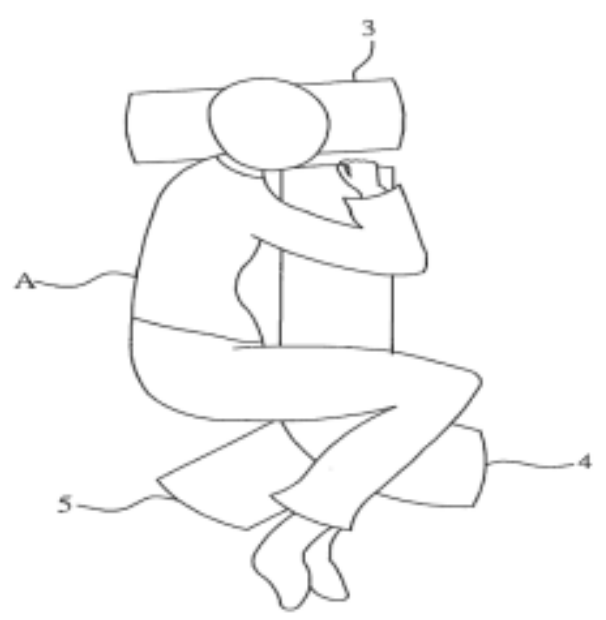


The above products have the following characteristics: the cotton fabric combination denim cloth with the anti-slippery and the tarpaulin under the elder's hips with the waterproofing functions could be removed and cleaned when they are dirty. Both sides of the handles in the tarpaulin only took 3 seconds to turn over the elders, which could save the energy and time of care workers. The cotton fabric combination denim cloth could be combined with the four positioning pillows, which could be put under the elder's back and hips. In addition, the large size of the J-shape pillow could be put between the elder's two legs. The functions of the four positioning pillows and the J-shape pillow are to decentralize the ergonomic pressure for the purpose of reducing the contracture of the body. Furthermore, the floral and shiny fabric of the outer layer and the soft cotton in the inner layer for the modified combination of turning and positioning auxiliary devices have fit into the beautiful and comfortable designs. Compared with the existed internet and patent products, the modified combination of turning and positioning auxiliary devices are more convenient for storage due to each part of devices being removable easily and quickly.

\section{Modified Urine Catheter Fixed Device}

The innovation of the urine catheter fixation device is rectangular and the material is elastic fabric with the length $13 \mathrm{~cm}$ and width $50 \mathrm{~cm}$, fixating by the left and right sides of velcros. The length 11 $\mathrm{cm}$ and width $7 \mathrm{~cm}$ of the velcros used the two reversed wire buckles to fix the catheter in the middle and the distance between the two wire buckles is $9 \mathrm{~cm}$. The following is the design, real product, and patent of modified fixed device. ${ }^{[8]}$

尿管固定
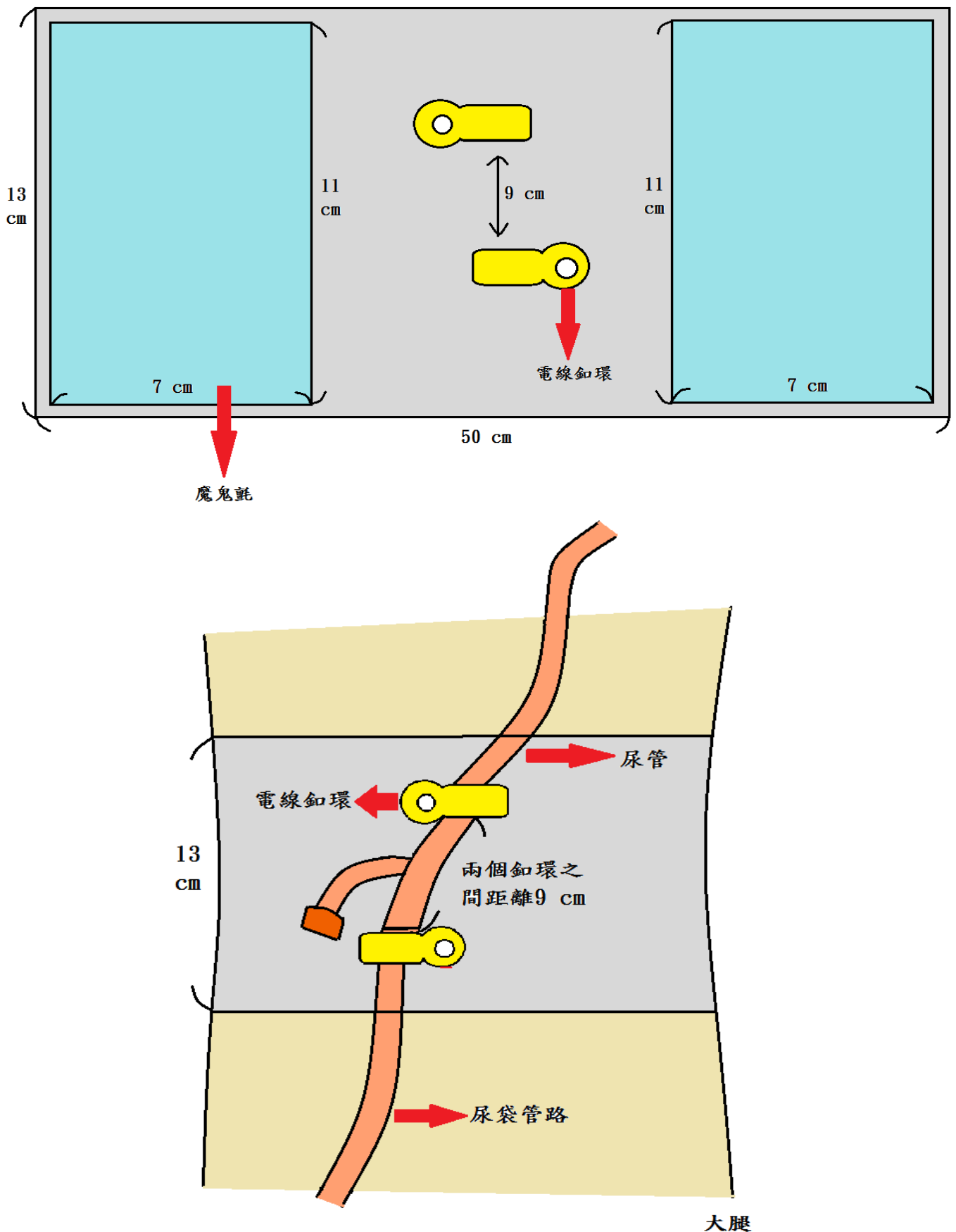


\section{International Journal of Innovative Research in Medical Science (IJIRMS) \\ Volume 03 Issue 08 August 2018, ISSN: 2455-8737, Imp. Factor - 4.102}

\section{Available online at - $\underline{w w w . j i j m s . i n}$}
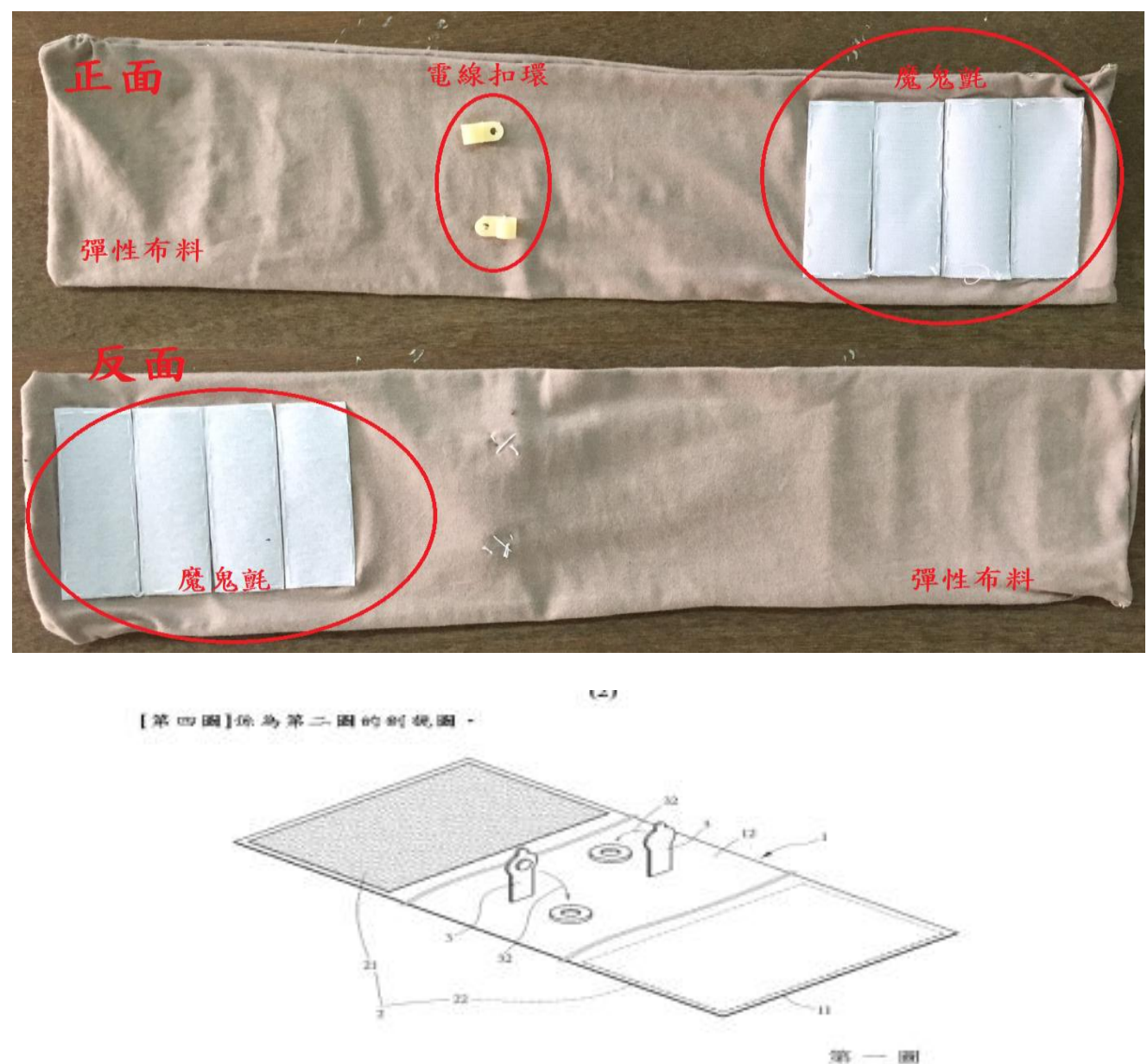

(3)

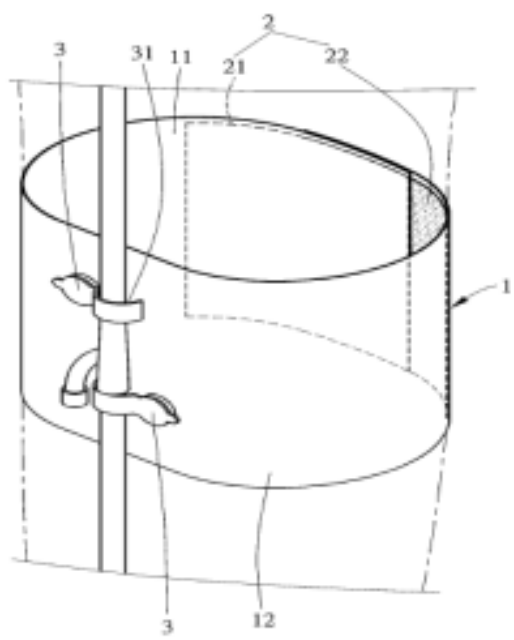

The urine catheter fixation device could reduce the pressure of skin friction in the leg of the elders. The characteristics of this innovative product include using the more solid and comfort materials, simplification of the design, and reduce the cost of $3 \mathrm{M}$ tapes for the elders who are used the installation urine bag for a long time.

\section{Conclusion}

The four innovative elderly products designed by the investigator and students in Taiwan have awarded by the Gold, Silver, and
Bronze Medals in 2017 International Innovation and Invention Competition in the Department of Nursing at Fooyin University during 2017.12.29 conducting by the organizations of Chinese Innovation and Invention Society and Moscow International Invention Society $[9,10,11]$. The plentiful outcomes both from the patents and awards do inspire the nursing faculty and students who are enthusiastically involved into the process of innovation and invention of products for the elders in the long-term care facilities as well as for the patients in the clinical settings. 
As the investigator reported in an article of the new era of nursing research, ${ }^{[12]}$ the team style of the good communication and partnership-relationship guiding by the leadership with the innovative strategies was suggested for the future nursing research. The author provided the series of innovative elderly products from their study team, and the process of transforming these innovative products into the patents and being awarded in the international innovative and invention competitions, which could provide as the references for those who are also interested in the innovative nursing studies. Following the four innovative elderly products, the investigator would plan to conduct the evidences-based testing of the effectiveness for these products to improve the quality of care for the bedridden elders in terms of preventing or solving their clinical problems such as bedsores, constipation, and comfort.

\section{References}

[1] Department of Statistics (2016). Monthly report of the interior statistics Jan-Nov. Retrieved from http://goo.gl/05L1A4

[2] National Development Council (2016). Population estimate of Taiwan (2016-2061). Retrieved from http://goo.gl/d4kckk

[3] Ku, Y. L. (correspondent), Lee, P. Y., Shen, M. H., \& Kuo, C. L. (2014). Constructing and Evaluating a Nursing Capstone Course for Cultivating Creativity in RN-BSN Students in Taiwan. Journal of Nursing Education and Practice, 4(7), 1-10.

[4] Lee, P. Y., Tu, C. T., Shen, M. H., \& Ku, Y. L. (correspondent) (2016).

Effectiveness of a nursing capstone project course in enhancing nursing student creativity. Innovative Journal of Medical and Health Science, 6(3), 69-75.

[5] The Modified Enema Device was innovated by Ku, Y. L. et al. with Patent Number M563884 in the Republic of China from 2018. 5.11. to 2027.12.17.

[6] The Turn Over Auxiliary Device was innovated by Ku, Y. L. et al. with Patent Number M559166 in the Republic of China from 2018. 5.01. to 2027.12.17.

[7] The Combination of Turn Over and Position Auxiliary Device was innovated by $\mathrm{Ku}, \mathrm{Y}$. L. et al. with Patent Number M546811 in the Republic of China from 2018. 8.11. to 2027.04.19.

[8] The Fixation of Tube and Line Device was innovated by $\mathrm{Ku}, \mathrm{Y}$. L. et al. with Patent Number M563883 in the Republic of China from 2018. 7.21. to 2027.12.11.

[9] The Modified Enema Device was awarded by the Gold Medal in 2017 International Innovation and Invention Competition by Ya-Lie Ku, Yi-Lun Li, Yi-Ching Wang, Yi-Ting Liang, Hsin-Ni Chiang, Department of Nursing, Fooyin University during 2017.12.29. Conducted by the organizations of Chinese Innovation and Invention Society and Moscow International Invention Society.

[10] The Modified Combination of Turn Over and Position Auxiliary Device was awarded by the Silver Medal in 2017 International Innovation and Invention Competition by Ya-Lie Ku, Yi-Ting Pan, Jo-Yun Shia, Ying-Chen Chen, Yen-Ying Chen, Yu-Jing Wei, Department of Nursing, Fooyin University during 2017.12.29. Conducted by the organizations of Chinese Innovation and Invention Society and Moscow International Invention Society.

[11] The Modified Fixed Devices was awarded by the Bronze Medal in 2017 International Innovation and Invention Competition by Ya-Lie Ku, Shu-Ting Hsu, Hui-Ru Hsu, Yu-Wei Lin, Wan-Qin Shen, Ting-Yu Fan, Department of Nursing, Fooyin University during 2017.12.29. Conducted by the organizations of Chinese Innovation and Invention Society and Moscow International Invention Society.

[12] Ku, Y. L. (2017). The new era of nursing research. COJ Nurse Healthcare, 1(1), 1-2.

\section{*Corresponding Author:}

Ya-Lie Ku, Associate Professor

Address: No. 151, Chin-Hsueh Rd., Ta-Liao District, Kaohsiung City 83102, Taiwan, ROC.

E-mail: $n s 126$ [at] fy.edu.tw 